\title{
Combination of BEZ235 and Metformin Has Synergistic Effect on Cell Viability in Colorectal Cancer Cells
}

\author{
Taewan Kim ${ }^{1}$, Taehyung Kim${ }^{1}$, Soonyoung Choi ${ }^{1}$, Hyeran Ko ${ }^{1}$, Deokbae Park² ${ }^{2}$, and ${ }^{\dagger}$ Youngki Lee $^{2}$ \\ ${ }^{1}$ Dept. of Medicine, Jeju National University School of Medicine, Jeju 63243, Korea \\ ${ }^{2}$ Dept. of Histology, Jeju National University School of Medicine, Jeju 63243, Korea
}

\begin{abstract}
Patients with type II diabetes mellitus are more susceptible to colorectal cancer (CRC) incidence than nondiabetics. The anti-diabetic drug metformin is most commonly prescribed for the treatment of this disease and has recently shown antitumor effect in preclinical studies. The aberrant mutational activation in the components of RAS/RAF/MEK/ERK and PI3K/AKT/mTOR signaling pathway is very frequently observed in CRC. We previously reported that metformin inhibits the phosphorylation of ERK and BEZ235, a dual inhibitor of PI3K and mTOR, has anti-tumor activity against HCT15 CRC cells harboring mutations of KRAS and PIK3CA. Therefore, we hypothesized that simultaneous inhibition of two pathways by combining metformin with BEZ235 could be more effective in the suppression of proliferation than single agent treatment in HCT15 CRC cells. Here, we investigated the combinatory effect of metformin and BEZ235 on the cell survival in HCT15 CRC cells. Our study shows that both of the two signaling pathways can be blocked by this combinational strategy: metformin suppressed both pathways by inhibiting the phosphorylation of ERK, 4E-BP1 and S6, and BEZ235 suppressed PI3K/AKT/ mTOR pathway by reducing the phosphorylation of 4E-BP1 and S6. This combination treatment synergistically reduced cell viability. The combination index (CI) values ranged from 0.44 to 0.88 , indicating synergism for the combination. These results offer a preclinical rationale for the potential therapeutic option for the treatment of CRC.
\end{abstract}

Key words : BEZ235, Metformin, HCT15 colorectal cancer cell, Cell viability

\section{INTRODUCTION}

Colorectal cancer (CRC), also known as colon cancer, is the third common type of cancer in humans with lifetime risk of 5\% (Siegel et al., 2017). Surgical resection and subsequent chemotherapy and/or radiotherapy are the traditional treatments for this cancer, but the use of chemotherapeutic drugs often is limited since these drugs are not specific to cancer cells but give severe toxic effects on normal proliferative cells such as intestinal gland cells. Over the last decades, new therapeutic regimens for CRC treatment such as molecular targeted therapy have been employed. However, as seen in almost all other cancers, drug resistance and serious side effects of drugs also occur, which result in the relapse of tumor and cessation of drug administration respectively (Britten, 2013). Thus, it is of clinical significance in the area of oncology to develop new therapeutic strategy to overcome drug resistance and reduce the incidents of side effects.

The PI3K/AKT/mTOR and RAS/RAF/MEK/ERK pathways play key roles in controlling cell survival, proliferation, differentiation and motility in response to various

\footnotetext{
Manuscript received May 30, 2018, Received in revised form June 8, 2018, Accepted June 14, 2018

${ }^{\dagger}$ Corresponding Author : Youngki Lee, Dept. of Histology, Jeju National University School of Medicine, Jeju 63243, Korea. Tel: +82- 64-754-3826, Fax: +82-64-702-2687, E-mail: yklee38@jejunu.ac.kr
}

This is an Open Access article distributed under the terms of the Creative Commons Attribution Non-Commercial License (http:// creative-commons.org/licenses/by-nc/3.0) which permits unrestricted non-commercial use, distribution, and reproduction in any medium, provided the original work is properly cited. 
growth factors (Mendoza et al., 2011). Aberrant regulation induced by gene mutation or amplification in the components of these signaling pathways is implicated in malignant transformation, tumorigenesis and drug resistance (McCubrey et al., 2007). Thus, much effort has been made to develop molecular inhibitors targeting these pathways (De Luca et al., 2012). During the last decade, simultaneous treatment with two pathway inhibitors has been suggested for more effective therapeutic intervention, since cross-talk and pathway convergence between these two pathways have been described and cancer cells with RAS mutation is capable of signaling through both pathways (Mendoza et al., 2011). However, the combined targeting strategy often proved to cause significant unacceptable drug-related toxicity, resulting in termination of clinical trials (Britten, 2013).

Metformin, a biguanide derivative, has been widely prescribed for treatment of type 2 diabetes mellitus for over 50 years and proved a well-tolerable drug with low cost. Several retrospective and case-control studies indicated that type 2 diabetes mellitus is associated with high risk for certain types of cancer including CRC (Larsson et al., 2005; MacKenzie et al., 2011), and metformin treatment in diabetic patients significantly reduced the risk of CRC compared with the control group (Tseng, 2012). Metformin usage in CRC patients with diabetic mellitus showed a $40 \%$ improvement in overall survival when compared with patients treated with the other antidiabetic agents (Garrett et al., 2012). In accordance with these studies of reduced cancer risk, metformin is activating AMP-activated protein kinase (AMPK) which is a central master of cellular energy metabolism, cell survival and proliferation (Griss et al., 2015). In preclinical studies, metformin exerts anti-proliferative effect in diverse cancer cells including CRC cells and inhibits tumor growth in vivo xenograft studies (Buzzai et al., 2007; Nangia-Makker et al., 2014). Moreover, many researchers showed that combined treatment of metformin with other chemotherapeutic and targeted agents synergistically increases the anticancer effect, suggesting the possibility to reduce the dose of drugs with severe toxicity (Iliopoulos et al., 2011; Zhang \& Guo, 2016).

In our previous studies using HCT15 CRC cells with coexistent mutations of KRAS and PIK3CA, we showed that metformin treatment decreases the level of pERK, one of the key regulatory components in RAS/RAF/MEK/ERK signaling pathway, and dual PI3K/mTOR inhibitor BEZ235 induces the inhibition of cell proliferation (Oh et al., 2016; Lee et al., 2017). Therefore, we hypothesized that the combination of metformin with BEZ235 could not only potentiate the anti-tumor activity as compared to single agent treatment, but also reduce serious side effects resulting from the combinational regimen which co-targets the two signaling pathways by using other inhibitors with severe toxicity. In the present study, we investigated 1) whether the combination of metformin with BEZ235 could lead to dual pathway inhibition, 2) whether the combination treatment regime would be more effective than either agent alone in inhibiting cell proliferation, and 3) whether the combination would change the pattern of cell cycle distribution in HCT15 CRC cells.

\section{MATERIALS AND METHODS}

\section{Reagents and cell culture}

The human colorectal cancer cell line HCT15 was purchased from American Type Culture Collection (Rockville, MD, USA). The cells were cultured in Dulbecco's modified Eagle's medium (DMEM) supplemented with $10 \%$ (vol/vol) heat inactivated fetal bovine serum (Gibco BRL, Rockville, MD, USA) and 1\% streptomycin/penicillin at $37^{\circ} \mathrm{C}$ in a humidified atmosphere consisting of $5 \% \mathrm{CO}_{2}$ and $95 \%$ air. Cells were maintained mycoplasma free by treating $5 \mu \mathrm{g} / \mathrm{mL}$ of Plasmocin (InvivoGen). BEZ235 was obtained from LC laboratories (Woburn, MA). The compound was initially dissolved in dimethyl sulfoxide 
(DMSO, Sigma-Aldrich, St. Louis, MO) to a concentration of $1 \mathrm{mM}$ and further diluted in DMEM media. Metformin (also known as 1,1-dimethylbiguanide hydrochloride) was purchased from Sigma-Aldrich and dissolved in DMEM media to a working concentration of $100 \mathrm{mM}$.

\section{Cell viability assay}

MTT assay was applied to measure cell viability as described previously (Lee et al., 2017). Briefly, cells were harvested and seeded in 24-well plates at a concentration of $5 \times 10^{4}$ cells/well for $24 \mathrm{hr}$. Then, cells were treated with increasing concentrations of BEZ235 (12.5-100 nM), metformin $(0.25-2 \mathrm{mM})$, their combinations or vehicle control for $48 \mathrm{hr}$. Experiments were performed in triplicate, each conducted in quadruplicate. The IC50 values (concentrations of drugs resulting in 50\% decrease in cell viability relative to controls), combination index (CI) and drug reduction index (DRI) were calculated using CompuSyn software (ComboSyn Inc, Paramus, NJ, USA). The CI value is a quantitative measure of the degree of drugs interaction. According to the recommendation of ChouTalalay (Chou \& Talalay, 1981), CI $<1$ indicates synergistic effects of drugs; $\mathrm{CI}=1$ indicates additive effect; $\mathrm{CI}>1$ indicates antagonism. DRI denotes how many folds of dose reduction are allowed for each drug due to synergism as compared to the dose of each drug alone.

\section{Western blotting}

Western blotting assays were carried out as previously described (Oh et al., 2016). Primary antibodies included pERK1/2 (Tyr204), ERK1/2, cyclin D1, cyclin B1 (all from Santa Cruz Biotechnology, Santa Cruz, CA, USA), and pRb (Ser807/811), p27 Kip1, p4E-BP1 (Ser65), 4EBP1, pS6 (Ser240/244), S6 (all from Cell Signaling Technology, MA, USA). Following incubation with secondary antibodies conjugated to horseradish peroxidase (Cell Signaling), immunoreactivity was detected with enhanced chemiluminescence method (Santa Cruz Biotechnology).

\section{Cell cycle analysis}

Flow cytometry to determine cell cycle distribution was performed as previously described (Lee et al., 2017). Briefly, cells were plated in six-well plates and treated with different concentrations of BEZ235, metformin, their combination and vehicle control for $48 \mathrm{hr}$. Cells were harvested and fixed overnight in $50 \%$ ethanol at $4^{\circ} \mathrm{C}$. Fixed cells were washed with cold PBS and incubated with RNase $(200 \mu \mathrm{g} / \mathrm{mL})$ for $30 \mathrm{~min}$ at $37^{\circ} \mathrm{C}$, and followed by propidium iodide staining. Cell cycle distribution was assayed using BD FACSCaalibur Flow Cytometry System and data were analyzed with CellQuest software (Becton Dickinson).

\section{Colony formation assay}

Cells were plated in 6-well culture dishes at a density of 200 cells per well. After $24 \mathrm{hr}$, cells were treated with BEZ235, metformin and their combination. Every three days, medium was changed with fresh medium containing the corresponding concentration of the drugs. Following twelve-day treatment, cell colonies were washed with cold PBS and then fixed with ice-cold $100 \%$ methanol and pictures were taken with a digital camera (Olympus).

\section{RESULTS}

1. Synergistic effects of metformin and BEZ235 on the growth inhibition of HCT15 CRC cells

To investigate whether metformin could affect the response of HCT15 CRC cells to BEZ235, we first monitored the alterations of the main downstream effector proteins of PI3K/AKT/mTOR and RAS/RAF/MEK/ERK pathways following treatment of metformin, BEZ235 or their combination for $24 \mathrm{hr}$. Single agent metformin showed significant effects on both pathways, where it markedly inhibited the phosphorylation of ERK of RAS/RAF/MEK/ ERK pathway as well as the phosphorylation of S6 and 4E-BP1 of PI3K/AKT/mTOR pathway (Fig. 1). On the 


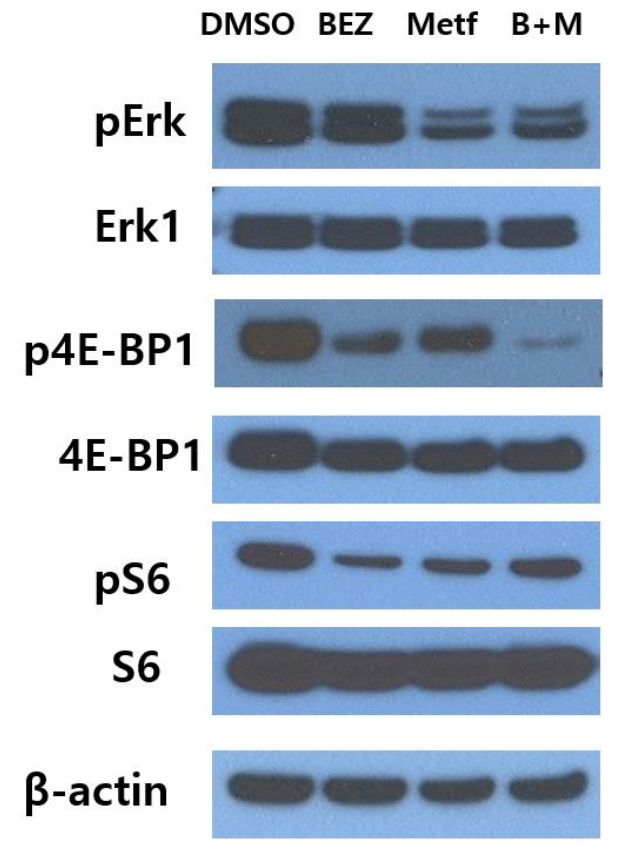

Fig. 1. Immunoblot analysis of effector proteins RAS/ RAF/MEK/ERK and PI3K/AKT/mTOR pathways. HCT15 CRC cells were treated with BEZ235 $(100 \mathrm{nM})$, metformin $(2 \mathrm{mM})$ and their combination for $24 \mathrm{hr}$. Phosphorylation was determined with antibodies against specific phospho-proteins compared to their total proteins. $\beta$-actin was used as a loading control. CRC, Colorectal cancer; DMSO, dimethyl sulfoxide; BEZ, BEZ235; Metf, Metformin.

other hand, single agent BEZ235 exerted little effect on the level of pERK, whereas it led to a significant inhibition of phosphorylation of S6 and 4E-BP1. The combination of BEZ235 and metformin showed a synergistic suppression of 4E-BP1 phosphorylation. However, the combination of BEZ235 and metformin did not lead to such a synergism in the levels of pERK and pS6 (Fig. 1).

Next, we analyzed the effect of metformin, BEZ235 or their combination on cell viability. HCT15 cells were incubated with various concentrations of drug alone or with their combinations for $72 \mathrm{hr}$, and cell viability was determined using MTT assay. Treatment with metformin or BEZ235 resulted in the inhibition of cell viability in a concentration-dependent manner. IC50 values (concentrations of drugs leading to $50 \%$ decrease in cell viability relative to controls) for metformin and BEZ235 were $2.47 \mathrm{mM}$ and $180.25 \mathrm{nM}$, respectively. The combined treatment of the two drugs showed more decrease in cell viability as compared to those obtained from treatment of metformin or BEZ235 alone (Fig. 2A).

To characterize the response of HCT15 CRC cells to the combination of metformin and BEZ235, we combined two drugs in a constant ratio to each other and calculated the CI and DRI using CompuSyn software. CI values ranged from 0.44 (for the combination of $1 \mathrm{mM}$ metformin and 50 $\mathrm{nM}$ BEZ235) to 0.88 (for the combination of $0.25 \mathrm{mM}$ metformin and $12.5 \mathrm{nM}$ BEZ235) and the CI value at ED50 was 0.68 , which indicate synergism according to the method of Chou-Talalay (Chou \& Talalay, 1981, Fig. 2B). We also found that the DRI values were always above 1 at any combination of two drugs (Fig. 2C).

\section{Effects of BEZ235, metformin and their combina-} tion on cell cycle

To delineate whether BEZ235, metformin and their combination exert growth inhibitory effects via the changes of cell cycle progression, we analyzed the cell cycle distribution by flow cytometry using PI staining, compared with the vehicle-treated control cells. HCT15 CRC cells treated with BEZ235 for $48 \mathrm{hr}$ displayed a prominent cell cycle arrest in $\mathrm{G}_{1}$ phase with decrease of the cell population in $S$ and $\mathrm{G}_{2} / \mathrm{M}$ phases. On the other hand, metformin caused a reduction of the cell population in $\mathrm{G}_{1}$ phase from $76.6 \%$ of control to $59.9 \%$. The decrease of cell population in $\mathrm{G}_{1}$ phase is accompanied by an increase of the cell population in $\mathrm{S}$ and $\mathrm{G}_{2} / \mathrm{M}$ phases, suggesting that metformin induces cell cycle arrest in $\mathrm{S}$ and $\mathrm{G}_{2} / \mathrm{M}$ phases. Of note, metformin led to a significant increase of sub- $\mathrm{G}_{1}$ cell population from $1.9 \%$ of control to $6.1 \%$, raising a possibility of apoptosis induction. Interestingly, the pattern of cell cycle distribution following BEZ235 and metformin co-treatment showed a remarka- 
(A)

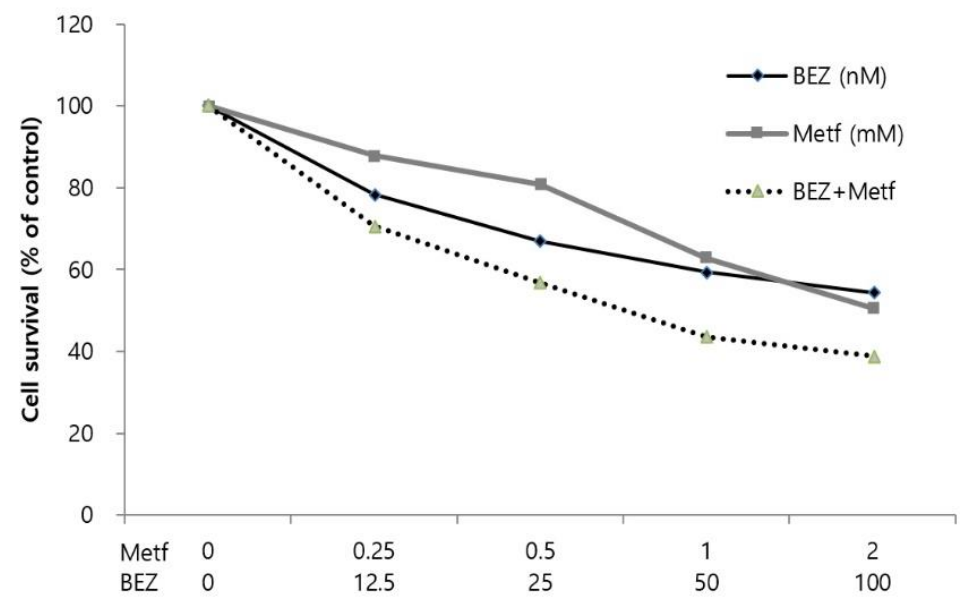

(B)

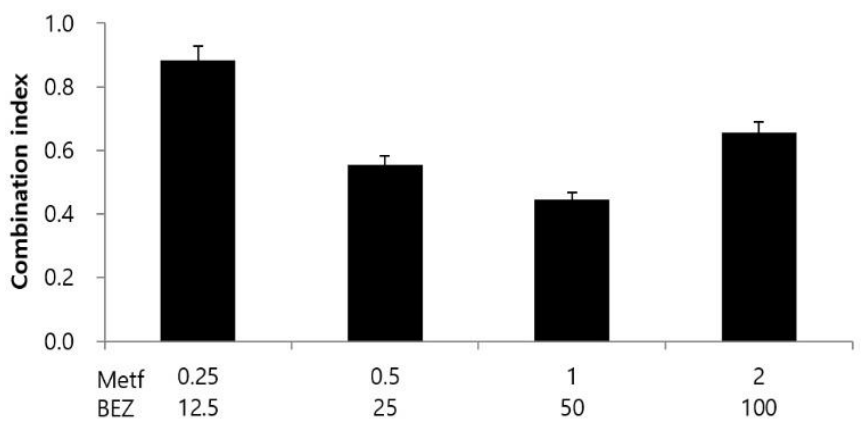

(C)

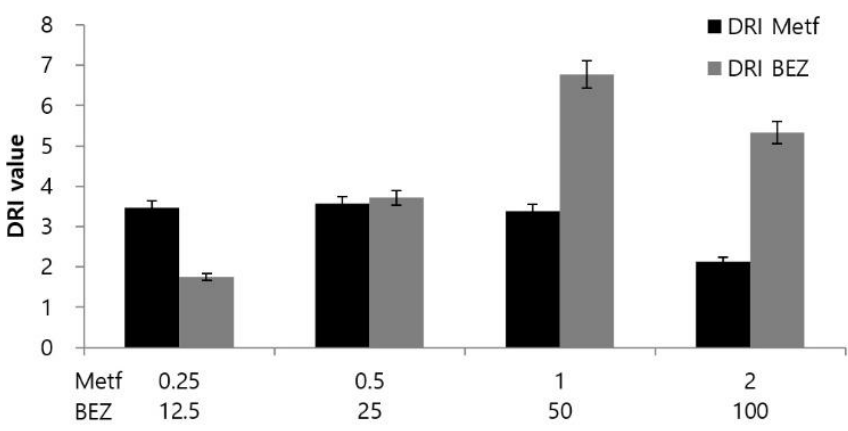

Fig. 2. Effect of BEZ235, metformin or their combination on cell viability. (A) Representative growth response curves for BEZ235, metformin and the combination in different ratios. HCT15 CRC cells were seeded at $5 \times 10^{4}$ cells/well $(0.5 \mathrm{~mL})$ in 24-well culture plates, incubated for $48 \mathrm{hr}$ and then treated with BEZ235, metformin and their combination for $48 \mathrm{hr}$. MTT assay was performed for the determination of cell viability. The viability of control cells was regarded as $100 \%$. (B) Combination index (CI) values for the various combination points of BEZ235 and metformin. The CI values, calculated by using CompuSyn software. (C) Drug reduction index (DRI) values of combination of BEZ235 and metformin. DRI values indicate how many folds of dose reduction are allowed for each drug due to synergism as compared to the dose of each drug alone. CRC, Colorectal cancer; BEZ, BEZ235; Metf, Metformin; DRI, drug reduction index.

ble reduction of cell population in $\mathrm{S}$ phase and increase of sub- $\mathrm{G}_{1}$ cell population as compared with metformintreated cells (Fig. 3).

We then examined the regulation of proteins involved in cell cycle by using immunoblot assay. Expression of cyclin $\mathrm{D}_{1}$ was down-regulated in HCT15 cells treated with BEZ235 or the combination of BEZ235 and metformin, but treatment with metformin alone did not show any sig- nificant change. The remarkable decrease in cyclin $\mathrm{B}_{1}$ levels was observed in cells treated with BEZ235, metformin and their combination. The phosphorylation of retinoblastoma tumor suppressor protein $(\mathrm{pRb})$ was increased by BEZ235 and reduced by metformin, while their combination markedly suppressed the level of pRb. P27 ${ }^{\text {Kip } 1}$, a member of the Cip/Kip family of cyclin-dependent kinase (cdk) inhibitors, was upregulated by BEZ235 and metfor- 

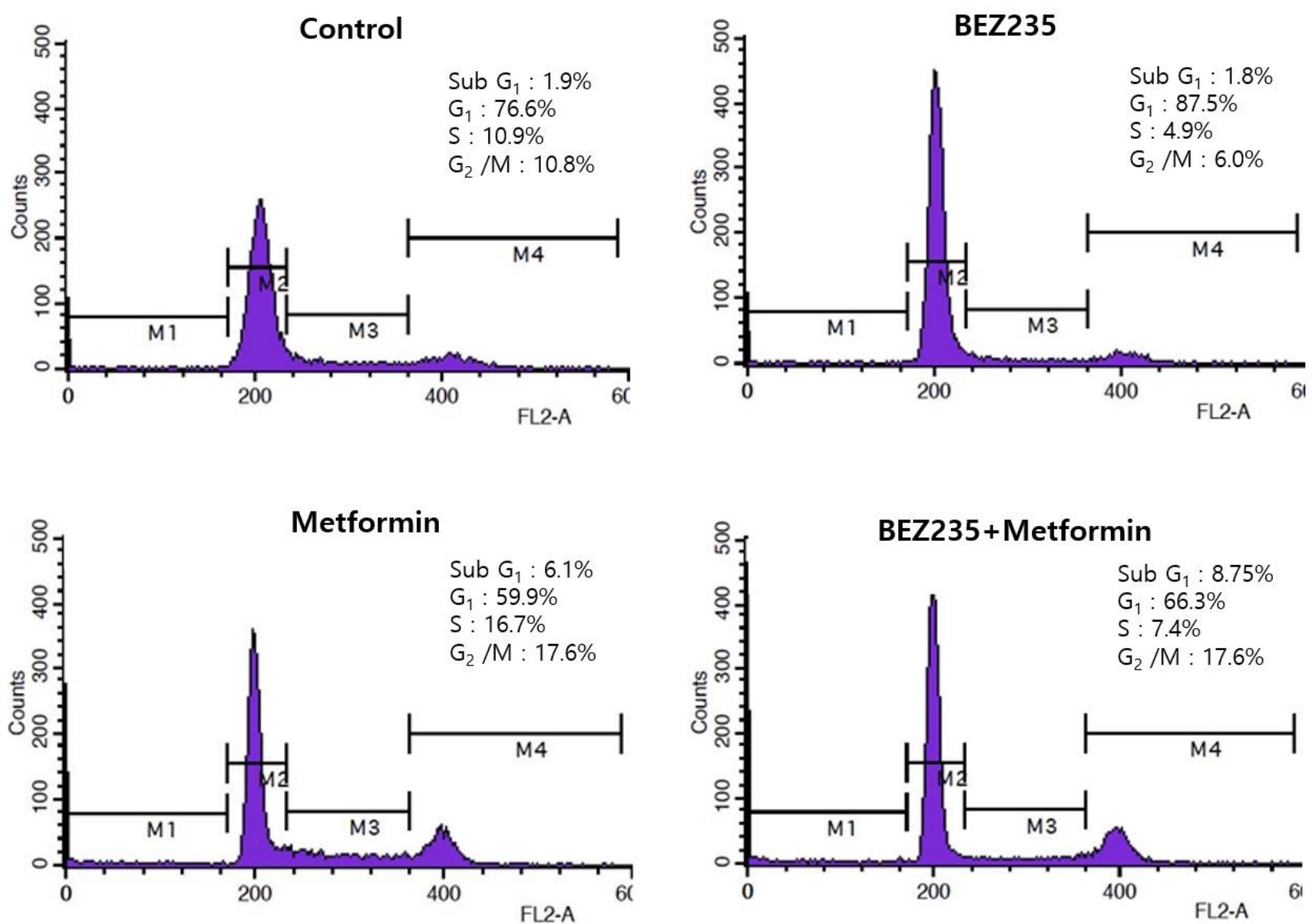

Fig. 3. Cell cycle analysis of HCT15 CRC cells. Cells were treated with BEZ235 (500 nM), metfromin (4 mM) and their combination for $48 \mathrm{hr}$. Cell cycle distributions were determined by flow cytometry after staining DNA with PI. CRC Colorectal cancer.

\section{CTL BEZ Metf B+M}

\section{CyclinD1}

\section{CyclinB1}

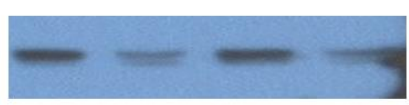

\section{pRb}

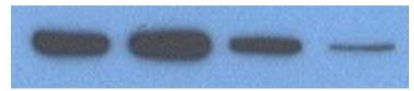

p27

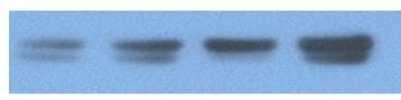

$\beta$-actin

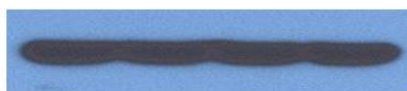

Fig. 4. Immunoblot analysis for proteins regulating cell cycle progression. Cells were treated with BEZ235 (100 $\mathrm{nM})$, metformin $(2 \mathrm{mM})$ and their combination for $24 \mathrm{hr}$. $\beta$-actin was used as a loading control. min, and the effect was further enforced by the combination of BEZ235 and metformin (Fig. 4).

3. Metformin potentiates the inhibitory effect of BEZ235 on the colony formation

We investigated whether metformin augments the antiproliferative activity of BEZ235 in the long term culture system using colony formation assay. As shown in Fig. 5, BEZ235 or metformin alone at the tested doses in a 12-day culture resulted in a partial inhibition of colony formation. On the other hand, the combined treatment with BEZ235 and metformin potentiated the inhibitory effect on the formation and growth of colonies when compared with either agent alone. Thus, these results further support the synergistic anti-proliferative effect of BEZ235 and metformin in 


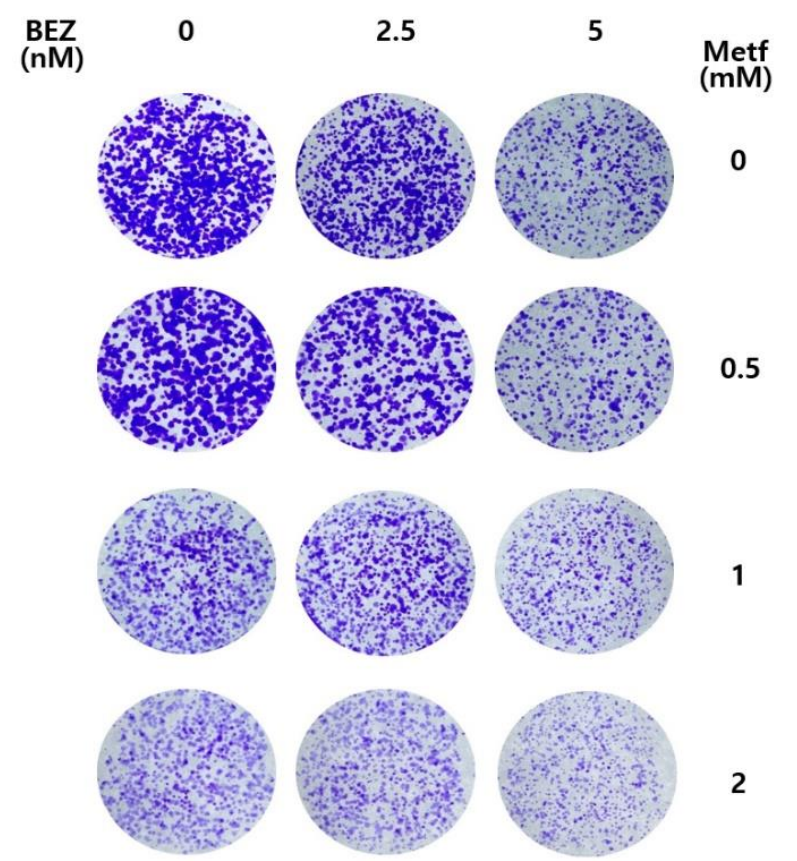

Fig. 5. Effect of combination of BEZ235 and metformin on colony formation in HCT15 cells. Cells were seeded in 6-well plates at a density of 200 cells per well. At $24 \mathrm{hr}$ after plating, cells were treated with indicated concentrations of BEZ235 and Metformin. Following 12-day treatment, cell colonies were stained using crystal violet dye and pictures were taken with a digital camera. BEZ, BEZ235; Metf, Metformin.

cell survival assay.

\section{DISCUSSION}

Cell survival and proliferation are mainly dependent on the regulation of RAS/RAF/MEK/ERK and PI3K/AKT/ mTOR cell signaling pathways, and alteration of downstream components of these signaling cascades, either through somatic mutation or epigenetic modification is often implicated in tumorigenesis (Liu et al., 2009; Santarpia et al., 2012). Although drugs targeting these pathways, developed and approved for treatment of cancer patients, showed remarkable responses in certain cancer types, many challenging issues such as drug resistance and side effects remain unresolved. Mechanistic studdies revealed the drug resistance is related to a negative crosstalk between two signaling pathways (Mendoza et al., 2011). Several preclinical studies using various cancer cells demonstrated that combined targeting of these two pathways is more effective in suppression of cancer cell proliferation compared to the single treatment groups (Britten, 2013; Posch et al., 2013). However, clinical trials of this co-targeting strategy achieved tumor regression to varied extent between 25 and 64\%, and the combination therapy caused severe drug-related toxicity in colorectal cancer patients (Shimizu et al., 2012).

In this study, we showed that metformin combined with BEZ235 is able to synergistically increase the anti-tumor activity in HCT15 CRC cells harboring both KRAS and PIK3CA mutations. CRC patients with KRAS mutations showed poorer overall survival and increased risk of relapse, especially when the conventional first-line chemotherapies have failed (Andreyeb et al., 1998). Moreover, targeted therapies against the epidermal growth factor receptor (EGFR) using cetuximab and panitumumab provide no benefit to CRC patients with KRAS mutations, although anti-EGFR treatment improves the response rate and overall survival in patients with KRAS-wild type CRC (Lievre et al., 2006; Benvenuti et al., 2007; Amado et al., 2008; Gong et al., 2016). Consequently, great effort has been made to develop drugs directly targeting KRAS and indirectly inhibiting the downstream effectors such as BRAF and MEK. To date, however, drug development to directly inhibit mutant RAS has failed. Monotherapy or combination therapy with inhibitors of BRAF and MEK did not show clinical efficacy in patients with KRAS mutation (Bennouna et al., 2011; Gong et al., 2016). Our previous studies using HCT15 CRC cell showed that metformin suppresses the phosphorylation of ERK and induces cell cycle arrest in S phase (Lee et al., 2017), and BEZ235, a dual inhibitor of PI3k and mTOR, produces $\mathrm{G}_{1}$ cell cycle arrest (Oh et al., 2016). Therefore, we reasoned that a combination of metformin and BEZ235 could provide 
more effective strategy to inhibit cell survival and proliferation in HCT15 CRC cell, and showed that the combination results in a synergistic inhibition of cell growth. We confirmed that the synergy is unlikely through enhanced suppression of pERK activation. Instead, our experimental results suggest that the combination induces synergistic inhibition of 4E-BP1 phosphorylation, implying the underlying mechanism of synergy may be related to the enhanced suppression of PI3K/AKT/mTOR pathway rather than that of RAS/RAF/MEK/ERK pathway. In addition, our cell cycle analysis with flow cytometry showed that treatment with BEZ235 and metformin leads to $G_{1}$ and $\mathrm{G}_{2} / \mathrm{M}$ arrest, respectively. Thus, another possible explanation for the synergistic effect would be that HCT15 cells with primary resistance to BEZ235 and thus escaping from $\mathrm{G}_{1}$ arrest are captured in the $\mathrm{G}_{2} / \mathrm{M}$ phase in response to metformin.

Metformin is a widely prescribed and well-tolerated drug for type II diabetes melitus. In cancer cells, metformin disrupts mitochondrial complex I (NADH dehydrogenase), leading to an increase in intracellular AMP/ATP ratio. The increased AMP/ATP ratio in turn activates AMPK (AMP-activated protein kinase), which results in inhibition of mTOR and subsequent suppression of the phosphorylation of its two downstream effectors, the 70 $\mathrm{kDa}$ ribosomal protein S6 kinase (p70S6K) and eukaryotic initiation factor 4E-binding protein (4E-BP1). Therefore, it has been suggested that the anticancer effect of metformin is mediated via interference with $\mathrm{PI} 3 \mathrm{~K} / \mathrm{AKT} / \mathrm{mTOR}$ pathway rather than RAS/RAF/MEK/ERK pathway (Mihaylova \& Shaw, 2011; Quinn et al., 2013). Here, our present result showed that metformin reduces the phosphorylation of ERK1/2 as well as S6 and 4E-BP1. We considered that metformin might increase the phosphorylation of ERK1/2 since these two pathways has been known to negatively regulate each other's activity via cross-inhibition (Mendoza et al., 2011). At present, we have no idea on this contradictory outcome. However, there are several studies show- ing the reduction of pERK in response to metformin (Niehr et al., 2011; Mohammed et al., 2013). Metformin leads to a dramatic reduction in epidermal growth factor activation and other receptor tyrosine kinases such as human epidermal growth receptor 2, which can inhibit the signaling through downstream pathways including the phosphorylation of ERK (Memmott et al., 2010; Ma et al., 2014). Metformin also suppressed tumor cell migration and invasion through inhibiting the phodphorylation of ERK (Hsieh et al., 2014). Of note, Niehr et al. (2011) and our unpublished in vitro studies showed that synergy obtained from combination of metformin with other targeted drugs is associated with reduction of $\mathrm{pERK}$ following metformin treatment. Thus, we tentatively suggest that the suppression of pERK in response to metformin could serve as a biomarker to predict potential synergism in the anticancer therapeutics using drug combination with metformin.

Taken together, our study provides evidence that the combination of an inhibitor of PI3K/AKT/mTOR pathway with metformin synergistically induces anticancer effects in HCT15 colorectal cancer cells with mutations of both KRAS and PIK3CA via suppression of pERK. Additional studies are needed to delineate the in vivo effect of our combination strategy, but our study suggests a possible therapeutic option for treatment of colorectal cancer, especially harboring KRAS mutation.

\section{ACKNOWLEDGEMENTS}

This research was supported by the 2017 scientific promotion program funded by Jeju National University.

\section{REFERENCES}

Amado RG, Wolf M, Peeters M, Van Cutsem E, Siena S, Freeman DJ, Juan T, Sikorski R, Suggs S, Radinsky R, Patterson SD, Chang DD (2008) Wild-type KRAS is required for panitumumab efficacy in patients with 
metastatic colorectal cancer. J Clin Oncol 26:16261634.

Andreyeb HJN, Norman AR, Cunningham D, Oates J, Clarke PA (1998) Kirsten ras mutations in patients with colorectal cancer: the multicenter "RASCAL" study. J Natl Cancer Inst 90:675-684.

Bennouna J, Lang I, Valladares-Ayerbes M, Boer K, Adenis A, Escudero P, Kim TY, Pover GM, Morris CD, Douillard JY (2011) A phase II, open-label, randomized study to assess the efficacy and safety of the MEK1/2 inhibitor AZD6244 (ARRY-142886) versus capecitabine monotherapy in patients with colorectal cancer who have failed one or two prior chemotherapeutic regimens. Invest New Drugs 29:1021-1028.

Benvenuti S, Sartore-Bianchi A, Di Nicolantonio F, Zanon C, Moroni M, Veronese S, Siena S, Bardelli A (2007) Oncogenic activation of the RAS/RAF signaling pathway impairs the response of metastatic colorectal cancers to anti-epidermal growth factor receptor antibody therapies. Cancer Res 67:2643-2648.

Britten CB (2013) PI3K and MEK inhibitor combinations: Examining the evidence in selected tumor types. Cancer Chemother Pharmacol 71:1395-1409.

Buzzai M, Jones RG, Amaravadi RK, Lum JJ, DeBerardinis RJ, Zhao F, Viollet B, Thompson CB (2007) Systemic treatment with the antidiabetic drug metformin selectively impairs p53-deficient tumor cell growth. Cancer Res 67:6745-6752.

Chou TC, Talalay P (1981) Generalized equations for the analysis of inhibitions of Michaelis-Menton and higher-order kinetic systems with two or more mutually exclusive and nonexclusive inhibitors. Eur $\mathrm{J}$ Biochem 115:207-216.

De Luca A, Maiello MR, D’Alessio A, Pergameno M, Normanno N (2012) The RAS/RAF/MEK/ERK and the PI3K/AKT signaling pathways: Role in cancer pathogenesis and implications for therapeutic approaches. Expert Opin Ther Targets 16(sup2):S17-S27.
Garrett CR, Hassalbo HM, Bhadkamkar NA, Wen S, Baladandayuthapani V, Kee BK, Eng C, Hassan MM (2012) Survival advantage observed with the use of metformin in patients with type II diabetes and colorectal cancer. Br J Cancer 106:1374-1378.

Gong J, Cho M, Fakih M (2016) RAS and BRAF in metastatic colorectal cancer management. J Gastrointest Oncol 7:687-704.

Griss T, Vincent EE, Egnatchik R, Chen J, Ma EH, Faubert B, Viollet B, DeBerardinis RJ, Jones RG (2015) Metformin antagonizes cancer cell proliferation by suppressing mitochondrial-dependent biosynthesis. Plos Biol 13:e1002309.

Hsieh SC, Tsai JP, Yang SF, Tang MJ, Hsieh YH (2014) Metformin inhibits the invasion of human hepatocellular carcinoma cells and enhances the chemosensitivity to sorafenib through a downregulation of the ERK/ JNK-mediated NF- $\kappa \mathrm{B}$-dependent pathway that reduces uPA and MMP-9 expression. Amino Acids 46:28092822.

Iliopoulos D, Hirsch HA, Struhl K (2011) Metformin decreases the dose of chemotherapy for prolonging tumor remission in mouse xenografts involving multiple cancer cell types. Cancer Res 71:3196-3201.

Larsson SC, Orsini N, Wolk A (2005) Diabetes mellitus and risk of colorectal cancer: A meta-analysis. J Natl Cancer Inst 97:1679-1687.

Lee J, Park D, Lee YK (2017) Metformin synergistically potentiates the antitumor effects of imatinib in colorectal cancer cells. Dev Reprod 21:139-150.

Lievre A, Bachet JB, Le Corre D, Boige V, Landi B, Emile JF, Cote JF, Tomasix G, Penna C, Ducreux M, Rougier P, Penault-LIorca F, Laurent-Puig P (2006) KRAS mutation status is predictive of response to cetuximab therapy in colorectal cancer. Cancer Res 66:3992-3995.

Liu P, Cheng H, Roberts TM, Zhao JJ (2009) Targeting the phosphoinositide 3-kinase pathway in cancer. Nat Rev Drug Discov 8:627-644. 
Ma J, Guo Y, Chen S, Zhong C, Xue Y, Zhang Y, Lai X, Wei Y, Yu S, Zhang J, Liu W (2014) Metformin enhances tamoxifen-mediated tumor growth inhibition in ER-positive breast carcinoma. BMC Cancer 14:172182.

MacKenzie T, Zens MS, Ferrara A, Schned A, Karagas MR (2011) Diabetes and risk of bladder cancer: Evidence from a case-control study in New Zealand. Cancer 117:1552-1556.

McCubrey JA, Steelman LS, Chappell WH, Abrams SL, Wong EWT, Chang F, Lehmann B, Terrian DM, Milella M, Tafuri A, Stivala F, Libra M, Basecke J, Evangelisti C, Martelli AM, Franklin RA (2007) Roles of RAF/MEK/ERK pathway in cell growth, malignant transformation and drug resistance. Biochim Biophys Acta 1773:1263-1284.

Memmott RM, Mercado JR, Maier CR, Kawabata S, Fox SD, Dennis PA (2010) Metformin prevents tobacco carcinogen-induced lung tumorigenesis. Cancer Prev Res 3:1066-1076.

Mendoza MC, Er EE, Blenis J (2011) The RAS-ERK and PI3K-mTOR pathways: Cross-talk and compensation. Trends Biochem Sci 36:320-327.

Mihaylova MM, Shaw RJ (2011) The AMPK signaling pathway coordinates cell growth, autophagy and metabolism. Nat Cell Biol 13:1016-1023.

Mohammed A, Janakiram NB, Brewer M, Ritchie RL, Marya A, Lightfoot S, Vernon ES, Rao CV (2013) Antidiabetic drug Metformin prevents progression of pancreatic cancer by targeting in part cancer stem cells and mTOR signaling. Transl Oncol 6:649-659.

Nangia-Makker P, Yu Y, Vasudevan A, Farhana L, Rajendra SG, Levi E, Majumdar APN (2014) Metformin: A potential therapeutic agent for recurrent colon cancer. PLoS One 9:e84369.

Niehr F, Euw E, Attar N, Guo D, Matsunaga D, Sazegar H, Ng C, Glaspy JA, Recio JA, Lo RS, Mischel PS,
Comin-Andix B, Ribas A (2011) Combination therapy with vemurafenib (PLX4032/RG7204) and metformin in melanoma cell lines with distinct driver mutations. J Transl Med 9:76-88.

Oh I, Cho H, Lee Y, Cheon M, Park D, Lee Y (2016) Blockage of autophagy rescues the dual PI3K/mTOR inhibitor BEZ235-induced growth inhibition of colorectal cancer cells. Dev Reprod 20:1-10.

Posch C, Moslehi H, Feeney L, Green GA, Ebaee A, Feichtenschlager V, Kim C, Peng L, Dimon MT, Phillips T, Daud AI, McCalmont TH, LeBoit PE, OrtizUrda S (2013) Combined targeting of MEK and $\mathrm{PI} 3 \mathrm{~K} / \mathrm{mTOR}$ effector pathways is necessary to effectively inhibit NRAS mutant melanoma in vitro and in vivo. Proc Natl Acad Sci USA 110:4015-4020.

Quinn BJ, Kitagawa H, Memmot RM, Gills JJ, Dennis PA (2013) Repositioning metformin for cancer prevention and treatment. Trends Endocrinol Metab 24:469-480.

Santarpia L, Lippman SM, El-Naggar AK (2012) Targeting of the MAPK-RAS-RAF signaling pathway in cancer therapy. Expert Opin Ther Targets 16:103-119.

Shimizu T, Tolcher AW, Papadopoulos KP, Beeram M, Rasco DW, Smith LS, Gunn S, Smetzer L, Mays TA, Kaiser B, Wick MJ, Alvarez C, Cavazos A, Mangold GL, Patnaik A (2012) The clinical effect of the dualtargeting strategy involving PI3K/AKT/mTOR and RAS/MEK/ERK pathways in patients with advanced cancer. Clin Cancer Res 18:2316-2325.

Siegel RL, Miller KD, Fedewa SA, Ahnen DJ, Meester RGS, Barzi A, Jemal A (2017) Colorectal cancer statistics, 2017. CA Cancer J Clin 67:177-193.

Tseng CH (2012) Diabetes, metformin use, and colon cancer: A population-based cohort study in Taiwan. Eur J Endocrinol 167:409-416.

Zhang HH, Guo XL (2016) Combinational strategies of metformin and chemotherapy in cancers. Cancer Chemother Pharmacol 78:13-26. 